\title{
Contributions of the Nanovoid Structure to the Kinetics of Moisture Transport in Epoxy Resins
}

\author{
CHRISTOPHER L. SOLES, ${ }^{1, *}$ FERNANDO T. CHANG, ${ }^{1}$ DAVID W. GIDLEY, ${ }^{2}$ ALBERT F. YEE ${ }^{1}$ \\ ${ }^{1}$ Department of Materials Science \& Engineering, University of Michigan, Ann Arbor, Michigan, 48109 \\ ${ }^{2}$ Department of Physics, University of Michigan, Ann Arbor, Michigan, 48109
}

Received 24 February 1999; revised 13 September 1999; accepted 13 December 1999

\begin{abstract}
Absorbed moisture can degrade the physical properties of an epoxy resin, jeopardizing the performance of an epoxy-based component. Although specific waterepoxy interactions are known to be very important in determining transport behavior, the role of network topology is not clear. In this article, a series of epoxies in which the topology is systematically varied (and the polarity held constant) is used to explore how topology influences the kinetics of moisture transport. The topology is quantified via the positron annihilation lifetime spectroscopy technique in terms of the size and volume fraction of electron density heterogeneities 5-6 $\AA$ in diameter, a dimension comparable to the $3-\AA ̊$ kinetic diameter of a water molecule. Surprisingly, the volume fraction of such nanopores does not affect the diffusion coefficient $(D)$ of water in any of the resins studied. For temperatures at and below $35{ }^{\circ} \mathrm{C}$, there is a mild exponential dependence of $D$ on the average nanopore size observed. Otherwise, the kinetics of moisture transport do not appear to depend on the nanopores. However, the initial flux of moisture into the epoxy does appear to correlate with the intrinsic hole volume fraction. That this correlation persists only in the initial stages of absorption is partially understood in terms of the ability of the water to alter the nanopore structure; only in the initial stages of uptake are the nanopores, as quantified in the dry state, relevant to transport. The role of specific epoxy-water interactions are also discussed in terms of transport kinetics. The lack of a correlation between the topology and transport suggests that polar interactions, and not topology, provide the rate-limiting step of transport. ( 2000 John Wiley \& Sons, Inc. J Polym Sci B: Polym Phys 38: 776-791, 2000

Keywords: moisture; absorption; transport; diffusion; positron annihilation lifetime spectroscopy; polymer; epoxy; topology
\end{abstract}

\section{INTRODUCTION}

The problem of moisture absorption in epoxy resins is one of significant technical importance. Epoxies can exhibit several attractive characteristics, including a high strength-to-weight ratio, ex-

Correspondence to: A. F. Yee (E-mail: afyee@engin. umich.edu)

* Present address: NIST, 100 Bureau Drive, Gaithersburg, $\mathrm{MD}, 20899-8541$

Journal of Polymer Science: Part B: Polymer Physics, Vol. 38, 776-791 (2000) (ㄷ) 2000 John Wiley \& Sons, Inc. cellent adhesion to many surfaces, superior thermal resistance, a relatively low dielectric constant, and ease of processing. This list of attributes has led to the widespread use of epoxies in a range of applications, including aerospace structural composites, adhesives, encapsulants for the microelectronics industry, lightweight composite infrastructures, and high-performance sporting goods. In each of these applications, exposure to a humid or moist environment is anticipated, and the typical epoxy will absorb from 1-7 percent water by weight. This absorbed moisture has deleterious effects on the physical properties 
of the epoxy and can greatly compromise the performance of the epoxy-based component. Some of the effects of absorbed moisture include a suppression of the glass-transition temperature $\left(T_{g}\right)$, that is, a decreased thermal stability; ${ }^{1}$ a decrease in yield strength, a change of the yield/deformation mechanisms, or both; ${ }^{2-9}$ moisture-induced swelling ${ }^{1,10-12}$ and swelling stresses; a degradation of fiber-matrix interfaces $;{ }^{13-18}$ the creation of microcracks or crazes, ${ }^{1,19-22}$ and chain scission through hydrolysis reactions. ${ }^{22,23}$ Clearly, one would like to control or inhibit moisture absorption to prevent these undesirable events from taking place.

To control moisture absorption in epoxy resins, the transport mechanisms must be understood. To this end, the topic of moisture absorption in epoxies has been studied for several decades, resulting in significant advances in our understanding. Most notably, resin polarity has been identified as being extremely important in determining transport properties. Water is a highly polar molecule, and specific water-epoxy interactions both increase uptake ${ }^{25,26}$ and retard transport kinetics. ${ }^{27} \mathrm{~A}$ vast majority of epoxies are cured with amine-based curing agents that result in hydroxyls and tertiary or secondary amines at the crosslink junctions. These species are also polar and demonstrate an affinity for water. This effect is understood, and group contribution theories provide a reasonable estimation of the equilibrium uptake based on the concentration of polar species. ${ }^{25-27}$

What remains to be shown is how topology influences moisture transport. By topology, we refer to the spatial or geometric characteristics of the covalent crosslink network. Different topologies can lead to a more open network that would seemingly be more amenable to the transport of small molecules such as water. The analogy is made between a crystalline polymer and amorphous polymer. In the crystalline phase, the packing is tight and efficient, rendering the material impermeable to most small molecules. However, the molecular packing of the amorphous phase is far less efficient, and small molecules can easily diffuse through the open spaces. The question here is how do different levels of openness in an amorphous epoxy influence transport behavior?

In part, the role of topology in the transport process is not clear because of a lack of experimental methods to accurately quantify this parameter. Generally, theoretical quantities must be invoked to describe the characteristics of topol- ogy, and, unfortunately, these parameters often elude verification by direct measurement. For example, the free-volume concept attempts to describe the openness of the topology in terms of the delocalized, unoccupied volume, and several theories attempt to relate the transport behavior to the free-volume content. However, one cannot directly measure the free volume, so these theories are difficult to critically test and refine.

In this study, we employed a relatively new experimental technique known as positron annihilation lifetime spectroscopy (PALS) to quantify both the size and number of nanometer-sized electron-deficient regions, or nanovoids, ranging from 2 to $20 \AA$ in diameter. As these dimensions are consistent with the unoccupied spaces in a typical polymeric material, this technique provides a method to quantify the topology or openness of the matrix on a local scale. These dimensions are also commensurate with the approximately $3-\AA$ kinetic diameter of a water molecule ${ }^{28,29}$ and should, therefore, be relevant to transport.

In a previous article, ${ }^{30}$ we introduced a series of epoxies in which the topology is systematically altered while the polarity is maintained constant by carefully adjusting both the flexibility of the amine-based curing agent and the crosslink density. The topology of these resins was studied at great length with the PALS technique, and correlations were made between the nanopore contents and the equilibrium moisture uptake. In this article, we extend this knowledge by examining how the kinetics of moisture transport depend on topology. This should deepen our understanding of the role of the nanopores in determining how much and how fast moisture is absorbed by the typical amine-cured epoxy.

\section{EXPERIMENTAL}

\section{Materials}

A detailed description of the material chemistry and preparation techniques is given in the previous article ${ }^{30}$ and is not repeated here. The interested reader is referred to this article for the details. The basic chemical structures and sample nomenclature are reproduced here in Figure 1. All the resins are mixed at stoichiometric ratios between the active hydrogen on the amines and the glycidal rings of the epoxy. The crosslink density is reduced by substitution of a fraction of the diamine curing agent with the analogous mono- 


\section{DER 332 - difunctional epoxy (with $\mathbf{n = 0}$ ):}<smiles>CC(O)(COc1ccc(C(C)(C)OCC2CO2)cc1)c1ccc(C(C)(C)c2ccc(C(C)(C)c3ccc(OCC4CO4)cc3)cc2)cc1</smiles>

RIGID series<smiles>Nc1ccc(Cc2ccc(N)cc2)cc1</smiles>

diamino diphenyl methane<smiles>Nc1ccccc1</smiles>
aniline

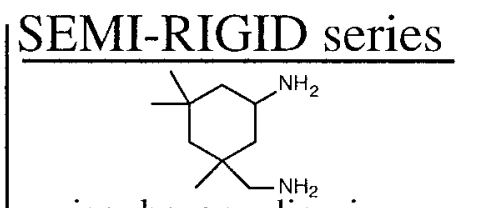

isophorone diamine<smiles>CC1CC(N)CC(C)(C)C1</smiles>

FLEXIBLE series

$$
\mathrm{H}_{2} \mathrm{~N}-\mathrm{C}_{2}-\mathrm{H}_{6}-\mathrm{NH}_{2}
$$

hexamethylene diamine

$$
\left.\mathrm{H}_{2} \mathrm{~N}-\mathrm{H}_{2}\right]_{6}^{-}-\mathrm{CH}_{3}
$$

hexamethylamine
NON-AMINE series

nadic methyl anhydride phenyl glycidal ether

\section{DER 661 - difunctional extended epoxy (with $n=2$ ):}<smiles>CC(C)(Oc1ccc(C(C)(C)c2ccc(OCC3CO3)cc2)cc1)c1ccc(C(C)(C)c2ccc(OCC3CO3)cc2)cc1</smiles>

\section{RIGID-EXTENDED series}<smiles>Nc1ccc(S(=O)(=O)c2ccc(N)cc2)cc1</smiles>

diamino diphenyl sulfone

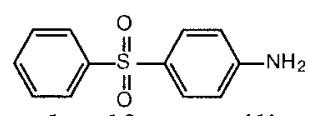

phenyl sulfone aniline

\section{Triphenyl trigylcidal ether - trifunctional epoxy:}

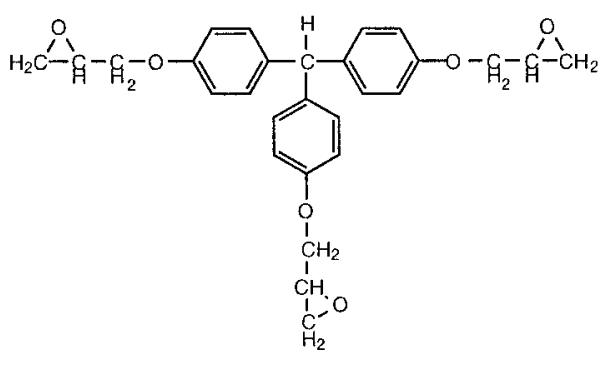

EXTRA-RIGID series<smiles>Nc1ccc(Cc2ccc(N)cc2)cc1</smiles>

diamino diphenyl methane

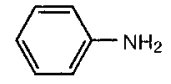

aniline

Figure 1. Molecular structures of the various epoxies and curing agents. The groupings indicate the diamine/monoamine pairs used with each epoxy as well as the nomenclature, underlined in block letters, to which each series is referred. 
Table I. Summary of the Glass-Transition Temperatures (Determined by Differential Scanning Calorimetry), Room Temperature Densities, and Typical PALS Hole Volume Fractions for the Resins Presented in Figure 1

\begin{tabular}{|c|c|c|c|c|c|}
\hline Sample & $\begin{array}{c}T_{g} \\
\left({ }^{\circ} \mathrm{C}\right)^{\mathrm{a}}\end{array}$ & $\begin{array}{c}\rho \\
\left(23^{\circ} \mathrm{C} ; \mathrm{g} / \mathrm{cm}^{3}\right)^{\mathrm{b}}\end{array}$ & $\begin{array}{c}V_{0} \\
(\operatorname{vol} \%)^{\mathrm{c}}\end{array}$ & $\begin{array}{c}V_{d} \\
\left(5^{\circ} \mathrm{C} ; \operatorname{vol} \%\right)^{\mathrm{c}}\end{array}$ & $\begin{array}{c}V_{d} \\
\left(90{ }^{\circ} \mathrm{C} ; \operatorname{vol} \%\right)^{\mathrm{c}}\end{array}$ \\
\hline Rigid $100 \%$ & 185 & 1.1927 & 2.57 & 1.73 & 3.03 \\
\hline Rigid $80 \%$ & 165 & 1.1936 & 2.36 & 2.61 & 4.21 \\
\hline Rigid $60 \%$ & 146 & 1.1932 & 1.75 & 1.65 & 2.63 \\
\hline Rigid $40 \%$ & 141 & 1.1915 & 1.67 & 1.92 & 3.07 \\
\hline Semirigid $100 \%$ & 170 & 1.1439 & 3.40 & 2.37 & 3.75 \\
\hline Semirigid $80 \%$ & 146 & 1.1213 & 2.97 & 2.43 & 3.95 \\
\hline Semirigid $60 \%$ & 136 & 1.1241 & 2.38 & 1.82 & 3.05 \\
\hline Semirigid $40 \%$ & 118 & 1.1145 & 2.30 & 2.41 & 3.75 \\
\hline Flexible $100 \%$ & 113 & 1.1653 & 2.33 & 2.36 & 3.97 \\
\hline Flexible $80 \%$ & 93 & 1.1530 & 1.52 & 2.04 & 3.56 \\
\hline Flexible $60 \%$ & 75 & 1.1423 & 1.48 & 2.77 & 4.91 \\
\hline Flexible $40 \%$ & 63 & 1.1321 & 1.23 & 3.61 & 6.68 \\
\hline Extended $100 \%$ & 130 & 1.2047 & 1.70 & 2.50 & 4.10 \\
\hline Extended $60 \%$ & 107 & 1.2090 & 1.67 & 2.27 & 3.69 \\
\hline Non-Amine $100 \%$ & 140 & 1.2081 & 1.47 & 1.99 & 2.90 \\
\hline Non-Amine $60 \%$ & 70 & 1.2216 & 1.21 & 1.93 & 4.15 \\
\hline Extrarigid $100 \%$ & - & 1.2310 & - & - & - \\
\hline Extrarigid $60 \%$ & 110 & 1.2066 & 2.07 & 2.60 & 4.36 \\
\hline
\end{tabular}
tions.

The percentages indicate that the fraction of stoichiometry matched with the diamine with the diamine/monoamine substitu-

a Typical error $= \pm 1$.

$\mathrm{b}$ Typical error $= \pm 0.0005$.

${ }^{\mathrm{c}}$ Typical error $= \pm 10 \%$.

amine chain extender. This ensures that the polar group (hydroxyl and amine) concentration remains essentially constant.

\section{PALS Experiments}

A detailed description of the fundamental physics underlying the PALS technique is not the purpose of this article. Several competent reviews on this topic have been written, ${ }^{31-33}$ and the interested reader is referred to one of these for more details. All that needs to be known here is that in the PALS technique, a positron enters the sample and forms a bound state with a free electron from the sample. This quasiparticle then localizes in the low electron density regions of the polymer, referred to as nanopores, and lives for a few nanoseconds before annihilating. The lifetime $\left(\tau_{3}\right)$ is proportional to the radius $(R)$ of the nanopore (see refs. 34 and 35 for details), thus conveying information about the volume of each nanopore $\left(v_{h}\right)$. Additionally, the relative number of annihilation events $\left(I_{3}\right)$ conveys information about the number of nanopores. Together, these quantities define the volume fraction of the nanopores $\left(V_{h}\right.$; assum- ing spherical nanopores) through the following relationships:

$$
\begin{aligned}
& V_{h}=C v_{h} I_{3} \\
& v_{h}=\frac{1}{2} \pi R^{3}
\end{aligned}
$$

where $C$ is a normalization constant.

The details of the PALS experiments and the normalization procedure are provided in the previous $\operatorname{article}^{30}$ and are not repeated here. The PALS experiments are performed as a function of temperature, and the hole volume $\left[V_{h}(T)\right]$ is extrapolated to absolute zero. The absolute zero hole volume fraction $\left(V_{0}\right)$ is defined as the intrinsic hole volume fraction, and at any temperature, the total hole volume fraction $\left[V_{h}(T)\right]$ is simply the sum of $V_{0}$ and $V_{d}(T) . V_{d}(T)$ is the dynamic hole volume fraction above and beyond $V_{0}$, resulting from thermal vibrations and molecular motions. Table I, reproduced from the previous article, shows how $V_{0}$ and $V_{d}(T)$ [and, thus, $V_{h}(T)$ ] vary between 5 and $90{ }^{\circ} \mathrm{C}$ for the resins presented in Figure 1. This table also indicates the various 
levels of crosslinking achieved in each resin series through monoamine/diamine substitutions.

\section{Diffusion Measurements}

A low-speed diamond wafering saw is used to cut the rigid, semirigid, and flexible resins of Figure 1 into $10 \times 10 \times 0.5 \mathrm{~mm}^{3}$ sections. Prior to the absorption experiments, samples are washed with soap and warm water, rinsed clean with water, and then dried for several days in a vacuum oven at $80^{\circ} \mathrm{C}$. The absorption experiments are for complete immersion in distilled water at 5, 35, 50, 70, and $90{ }^{\circ} \mathrm{C}$. Before the sample is placed in water, the dry weight is recorded on a Perkin-Elmer AD-4 autobalance. The moisture uptake as a function of immersion time is monitored by the periodic removal of the sample, blotting of the excess moisture, and recording of the weight. Eventually, the weight gain reaches a plateau value that is taken as the equilibrium moisture uptake.

The procedures for the rigid-extended, nonamine, and extrarigid resin absorption experiments are analogous, with the exception of the sample dimensions, thermal history, and temperatures tested. For these resins, larger $20 \times 20$ $\times 0.3 \mathrm{~mm}^{3}$ samples are employed. Prior to absorption, the samples are heated to $T_{g}+20^{\circ} \mathrm{C}$ for $24 \mathrm{~h}$ in a vacuum and then quenched to room temperature to establish a well-defined thermal history. The absorption experiments are performed only at 5,50 , and $90{ }^{\circ} \mathrm{C}$ under the conditions of complete immersion in distilled water.

The diffusion coefficients are easily calculated from the moisture-uptake profiles with a Fickian diffusion equation: ${ }^{36}$

$$
\frac{M_{t}}{M_{\infty}}=4\left(\frac{D t}{h^{2}}\right)^{1 / 2}\left[\frac{1}{\pi^{1 / 2}+2} \sum_{n=1}^{\infty}(-1)^{n} \text { ierfc } \frac{n h}{2(D t)^{1 / 2}}\right]
$$

where $M_{t}$ is the moisture uptake at time $t, M_{\infty}$ is the equilibrium moisture uptake, $h$ is the sample thickness, and $D$ is the diffusion coefficient. This solution of Fick's second law holds true for the conditions of an infinite sheet with constant penetrant activity on both sides of the sheet and a concentration independent of $D$. At very short times, where $M_{t} / M_{\infty}$ is less than 0.5 , eq 3 can be approximated by the following: ${ }^{36}$

$$
\frac{M_{t}}{M_{\infty}}=\frac{4}{h} \sqrt{\frac{D t}{\pi}}
$$

Equation 4 is easily rearranged to reveal that the initial slope in a plot of $M_{t} / M_{\infty}$ versus $\sqrt{ } t / h$ is related to the diffusion coefficient $D$ through the following:

$$
D=\frac{\pi}{16}\left(\frac{M_{t} / M_{\infty}}{\sqrt{t} / h}\right)^{2}
$$

As with the equilibrium-uptake data, the diffusion coefficients are calculated at $5,35,50,70$, and $90{ }^{\circ} \mathrm{C}$ for the rigid, semirigid, and flexible resins. For each resin and temperature combination, the diffusion coefficient is an average of five independent samples. The rigid-extended, extrarigid, and non-amine resins are measured at 5, 50 , and $90{ }^{\circ} \mathrm{C}$ only, with the diffusion coefficient being an average of three samples, not five.

In a select group of materials, the diffusion coefficients are also determined in both the absorption and desorption modes. These materials include the $80 \%$ rigid, $40 \%$ semirigid, $60 \%$ flexible, $100 \%$ non-amine, and $100 \%$ crosslinked extrarigid resins. These experiments are performed at 35,50 , and $70{ }^{\circ} \mathrm{C}$ with the absorption phase conducted at $100 \%$ relative humidity. For desorption, the equilibrium weight loss is assumed to be equal to the equilibrium-uptake value for the absorption phase. $M_{t}$ in eq 5 is taken as the mass of the water lost (not gained) as a function of time. The assumption of equal $M_{\infty}$ values implies that all of the water taken on during absorption is released on desorption. The desorption phase is performed in a Blue $\mathrm{M}$ convection oven that continually circulates heated air over the sample. No attempts are made to control the relative humidity of this air. As with the absorption measurements, samples are periodically removed from the oven and weighed on a Perkin-Elmer AD4 autobalance until the weight loss stabilizes. The stabilized value is generally very close to the initial dry weight, with any variations attributed to fluctuations in the relative humidity of the building.

\section{RESULTS}

Figure 2 demonstrates the use of eq 5 to determine the diffusion coefficient. The mass of absorbed moisture in the $60 \%$ crosslinked rigid resin is plotted as a function of the square root of the absorption time divided by the sample thickness. By recording the initial slope and the equilibrium uptake, one can determine $D$ as follows: 


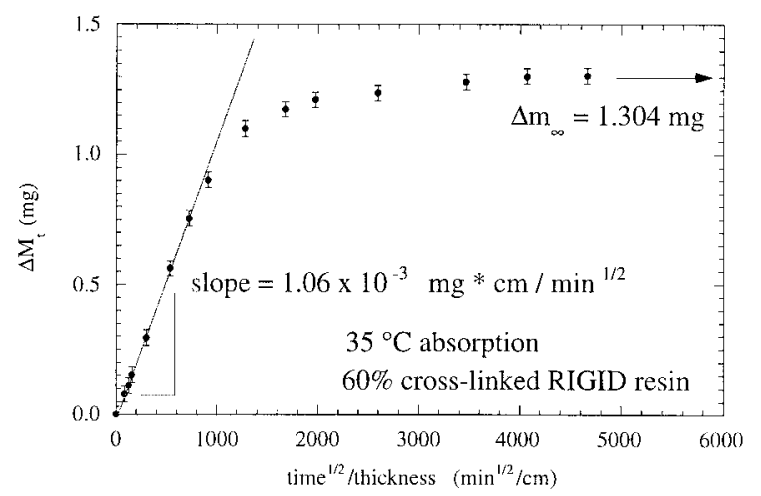

Figure 2. An example of the parameters needed to calculate the diffusion coefficient according to eq 5 . The initial slope and equilibrium uptake are easily determined, in this case for a $60 \%$ crosslinked rigid resin at $35{ }^{\circ} \mathrm{C}$.

$$
\begin{aligned}
& D=\frac{\pi}{16 M_{\infty}^{2}}\left(\frac{M_{t}}{\sqrt{t} / h}\right)^{2} \\
& D=\frac{\pi}{16(1.304)^{2}}\left(1.06 \times 10^{-3}\right)^{2} \\
& D=1.30 \times 10^{-7} \mathrm{~cm}^{2} / \mathrm{min}
\end{aligned}
$$

$$
D=2.16 \times 10^{-9} \mathrm{~cm}^{2} / \mathrm{sec}
$$

With this method, the diffusion coefficient as a function of temperature is determined for all of the resins in Figure 1, and the average values are reported in Table II.

A typical set of moisture-uptake curves is presented in Figure 3(a) for the 60\% crosslinked rigid resin at $70{ }^{\circ} \mathrm{C}$. Five independent samples are included in this curve, with the solid line indicating theoretical Fickian behavior. The Fickian profile is generated through a relationship developed by Shen and Springer ${ }^{37}$ that simplifies the infinite series of eq 1 to the following:

$$
\frac{\Delta M_{t}}{\Delta M_{\infty}}=1-\exp \left[-7.3\left(\frac{D t}{h^{2}}\right)^{0.75}\right]
$$

Although there is little variation between the five separate samples, the profiles do not entirely conform to Fickian behavior. Other examples of deviations from Fickian behavior are illustrated next.

\begin{tabular}{|c|c|c|c|c|c|}
\hline \multirow[b]{2}{*}{ Sample } & \multicolumn{5}{|c|}{ Diffusion Coefficients $\left(\mathrm{cm}^{2} / \mathrm{sec}\right)^{\mathrm{a}}$} \\
\hline & $5{ }^{\circ} \mathrm{C}$ & $35^{\circ} \mathrm{C}$ & $50^{\circ} \mathrm{C}$ & $70^{\circ} \mathrm{C}$ & $90^{\circ} \mathrm{C}$ \\
\hline Rigid $100 \%$ & $3.29 \times 10^{-10}$ & $2.77 \times 10^{-9}$ & $7.40 \times 10^{-9}$ & $1.74 \times 10^{-8}$ & $3.07 \times 10^{-8}$ \\
\hline Rigid $80 \%$ & $3.46 \times 10^{-10}$ & $2.72 \times 10^{-9}$ & $7.17 \times 10^{-9}$ & $1.66 \times 10^{-8}$ & $3.03 \times 10^{-8}$ \\
\hline Rigid $60 \%$ & $3.05 \times 10^{-10}$ & $2.49 \times 10^{-9}$ & $6.54 \times 10^{-9}$ & $1.52 \times 10^{-8}$ & $2.71 \times 10^{-8}$ \\
\hline Rigid $40 \%$ & $3.49 \times 10^{-10}$ & $2.49 \times 10^{-9}$ & $6.15 \times 10^{-9}$ & $1.43 \times 10^{-8}$ & $2.52 \times 10^{-8}$ \\
\hline Semirigid $100 \%$ & $4.08 \times 10^{-10}$ & $3.74 \times 10^{-9}$ & $8.07 \times 10^{-9}$ & $1.27 \times 10^{-8}$ & $3.15 \times 10^{-8}$ \\
\hline Semirigid $80 \%$ & $4.36 \times 10^{-10}$ & $3.41 \times 10^{-9}$ & $8.20 \times 10^{-9}$ & $1.35 \times 10^{-8}$ & $3.26 \times 10^{-8}$ \\
\hline Semirigid $60 \%$ & $5.47 \times 10^{-10}$ & $3.30 \times 10^{-9}$ & $5.32 \times 10^{-9}$ & $1.30 \times 10^{-8}$ & $4.06 \times 10^{-8}$ \\
\hline Semirigid $40 \%$ & $5.66 \times 10^{-10}$ & $3.21 \times 10^{-9}$ & $5.27 \times 10^{-9}$ & $1.37 \times 10^{-8}$ & $3.97 \times 10^{-8}$ \\
\hline Flexible $100 \%$ & $2.46 \times 10^{-10}$ & $1.61 \times 10^{-9}$ & $4.70 \times 10^{-9}$ & $1.44 \times 10^{-8}$ & $5.27 \times 10^{-8}$ \\
\hline Flexible $80 \%$ & $3.17 \times 10^{-10}$ & $1.62 \times 10^{-9}$ & $5.57 \times 10^{-9}$ & $1.55 \times 10^{-8}$ & $6.05 \times 10^{-8}$ \\
\hline Flexible $60 \%$ & $3.96 \times 10^{-10}$ & $2.05 \times 10^{-9}$ & $7.50 \times 10^{-9}$ & $3.31 \times 10^{-8}$ & $9.38 \times 10^{-8}$ \\
\hline Flexible $40 \%$ & $4.58 \times 10^{-10}$ & $3.21 \times 10^{-9}$ & $1.21 \times 10^{-8}$ & $5.09 \times 10^{-8}$ & $1.37 \times 10^{-7}$ \\
\hline Rigid-Extended $100 \%$ & $4.5 \times 10^{-10}$ & - & $8.2 \times 10^{-9}$ & - & $6.6 \times 10^{-8}$ \\
\hline Rigid-Extended $60 \%$ & $2.9 \times 10^{-10}$ & - & $6.4 \times 10^{-9}$ & - & $6.3 \times 10^{-8}$ \\
\hline Extrarigid $100 \%$ & $3.0 \times 10^{-10}$ & - & $5.9 \times 10^{-9}$ & - & $3.2 \times 10^{-8}$ \\
\hline Extrarigid $60 \%$ & $2.5 \times 10^{-10}$ & - & $5.4 \times 10^{-9}$ & - & $3.0 \times 10^{-8}$ \\
\hline Non-Amine $100 \%$ & $2.1 \times 10^{-9}$ & - & $2.0 \times 10^{-8}$ & - & $9.2 \times 10^{-8}$ \\
\hline Non-Amine $60 \%$ & $9.2 \times 10^{-10}$ & - & $1.6 \times 10^{-8}$ & - & - \\
\hline
\end{tabular}

In the discussion of the thermal jump experiments in the previous publication, ${ }^{30}$ the weight

Table II. A Complete Listing of the Diffusion Coefficients as a Function of Temperature for All of the Resins Presented in Figure 1

For the rigid, semirigid, and flexible resins, each diffusion coefficient is the average of five independent samples; for the remaining resins, each diffusion coefficient is the average of three samples.

a Typical error $= \pm 20 \%$. 
(a)

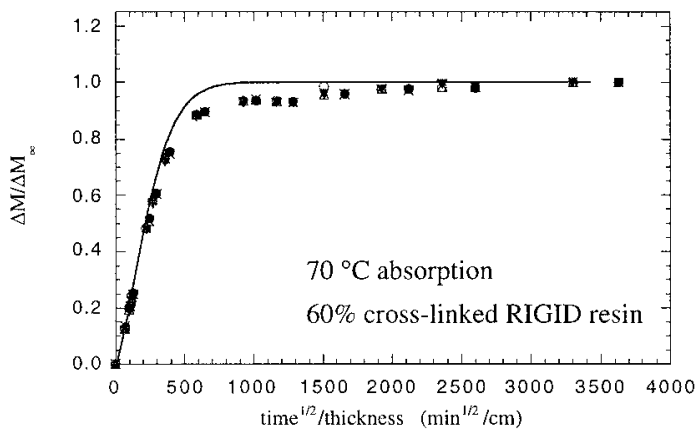

(b)

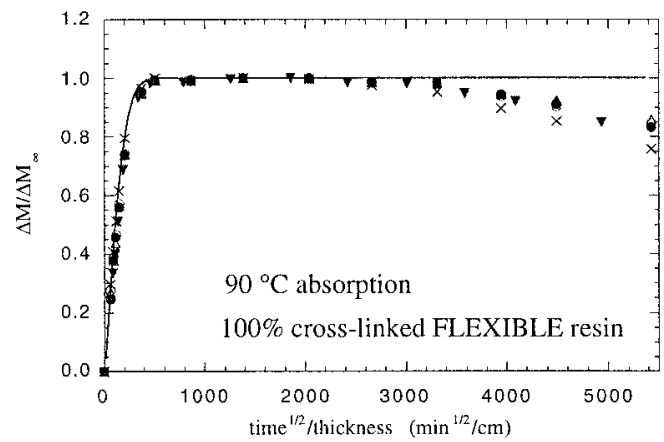

(c)

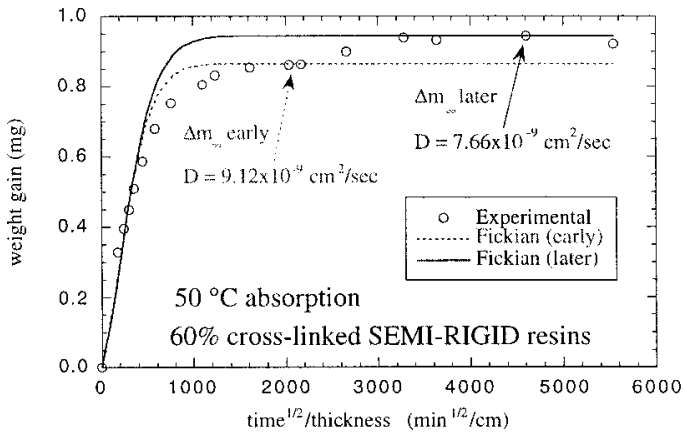

Figure 3. Various examples of moisture-uptake profiles that deviate from true Fickian behavior. (a) Data from five independent samples show that although the measurements are very reproducible, deviations from true Fickian behavior are encountered in the intermediate stages of uptake. (b) Long-term degradation can also occur in some of the lower $T_{g}$ networks and lead to deviations from Fickian behavior. (c) A misjudgment in equilibrium weight gain may lead to as much as a $20 \%$ difference in the Fickian diffusion coefficient.

gain of the flexible resin reached a maximum followed by a gentle decrease at long absorption times. The profile in Figure 3(b) depicts the 100\% crosslinked flexible resin at $90{ }^{\circ} \mathrm{C}$ where the uptake goes through a similar maximum. This clearly leads to deviations from Fickian behavior at long times. Degradation of the network could explain such deviations at long times. In most epoxies, a $100 \%$ theoretical conversion of the ep- oxy-amine reaction is rarely achieved. Solid-state NMR work by Merritt et al. ${ }^{38}$ on a similar flexible resin indicated that the crosslink index is approximately 0.90 . In such low- $T_{g}$ resins, it is plausible that water can leach unreacted, low molecular weight species from the sample. It is also feasible that such low molecular weight species can be created through a hydrolysis reactions of the following type: $:^{23,24}$

$$
\begin{aligned}
\sim \sim \sim \mathrm{A}-\mathrm{B} \sim \sim \sim & +\mathrm{H}_{2} \mathrm{O} \Rightarrow \\
& \sim \sim \sim \mathrm{A}-\mathrm{H}+\mathrm{HO}-\mathrm{B} \sim \sim \sim
\end{aligned}
$$

where A and B are substituents of the epoxy network. In the presence of such a maximum in the uptake, the peak value is taken as the equilibrium moisture uptake because the long-term degradation properties are not of interest.

Sometimes, it is difficult to absolutely determine the equilibrium-uptake plateau. Rather than showing a true plateau, the long-term uptake can exhibit either a gentle decrease (discussed previously) or increase. This leads to errors in determining the diffusion coefficient. To asses the possible errors in underestimating the equilibrium uptake, Figure 3(c) demonstrates how a premature choice of $\Delta M_{\infty}$ can lead to as much as a $20 \%$ difference in $D$. Clearly, throughout Figure 3(a,c), the diffusion profiles do not rigorously adhere to Fickian behavior. Further evidence of this is observed in the initial linear portion of the uptake curves. Although eq 5 dictates linearity for $M_{t} / M_{\infty} \leq 0.5$, most resins exhibit linearity to higher $M_{t} / M_{\infty}$ values. This is a signature of $D$ being an increasing function of concentration $^{36}$ (if $D$ were a decreasing function of concentration, $M_{t} / M_{\infty}$ would deviate from linearity at a value lower than 0.5 ). As true Fickian behavior is not observed, the liberal error estimate of $20 \%$ determined in Figure 3(c) will be assigned to all of the diffusion coefficient calculations. This prevents overinterpretation of the "Fickian" diffusion coefficients and also accounts for possible errors in choosing $\Delta M_{\infty}$. However, the error in judgment depicted in Figure 3(c) represents a worst case scenario, and $\Delta M_{\infty}$ is typically determined with greater accuracy.

To correlate the kinetics of transport to topology, the diffusion coefficients in Table II are analyzed in terms of the nanopore characteristics. Figure 4(a) presents $D$ as a function of $\tau_{3}$, proportional to the average nanopore radius, for the rigid, semirigid, and flexible resins. The dashed 

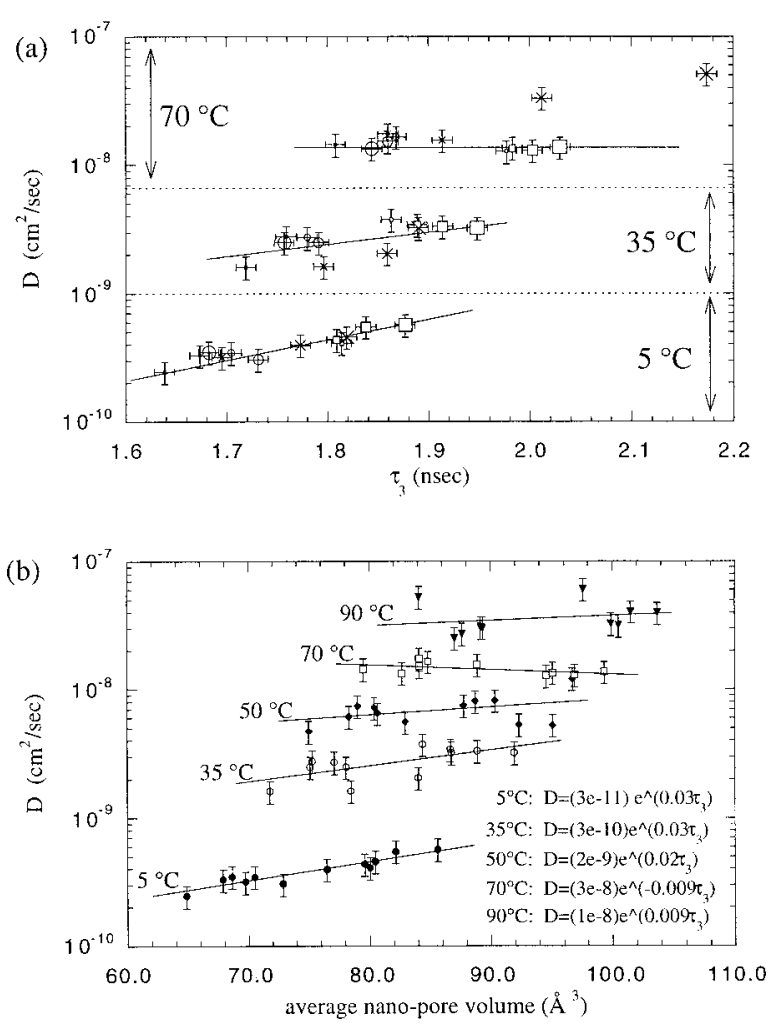

Figure 4. (a) The moisture diffusion coefficients are plotted as a function of $\tau_{3}$ for the rigid (circles), semirigid (squares), and flexible (X's) resins. As the size of the data marker decreases, the degree of crosslinking increases in the following order: 40, 60, 80, and $100 \%$. The dashed lines denote isothermal groupings. (b) The variable $\tau_{3}$ is converted into an average nanopore volume, and the distinction between the different resins is dropped. The only distinctions made are between isothermal measurements, with an exponential curve fit applied at each temperature.

lines nominally divide the graph into three regions for isothermal measurements at 5, 35, and $70{ }^{\circ} \mathrm{C}$. Within each isothermal grouping, three types of data markers are present. The circles, squares, and X's correspond to the rigid, semirigid, and flexible resins, respectively. For each family of resins (e.g., rigid resins), the size of the marker is indicative of the crosslink density. Marker sizes of $6,9,12$, and 15 points represent $100,80,60$, and $40 \%$ crosslinking, respectively (the smallest markers indicate the highest crosslink densities). Unfortunately, this is an extremely complicated representation of the data. However, it is important to realize there are two ways to increase $\tau_{3}$. For a single resin (e.g., follow the $40 \%$ semirigid resin, the biggest squares), $\tau_{3}$ increases with temperature. Of course, this is also accompanied by a significant increase in the diffusion coefficient as diffusion is a thermally activated process. However, one can isothermally change the topology, that is, $\tau_{3}$, by varying the crosslink density and curing-agent architecture. For evaluating the role of topology, this latter method is advantageous because the effects are not convoluted with the thermal activation of diffusion process.

As $\tau_{3}$ is increased thermally, the diffusion coefficient increases dramatically. For such changes, $\tau_{3}$ primarily reflects the changes in temperature as the nanopores expand more or less linearly with temperature below the $T_{g}$. Although it is not shown here, a plot of $\ln (D)$ versus $1 / T$ yields a straight line, consistent with an Arrhenius-activated process. In this respect, the isothermal influences of $\tau_{3}$ on $D$ are more interesting. At $5{ }^{\circ} \mathrm{C}$, a slight linear dependence of $\ln (D)$ on $\tau_{3}$ is observed. However, as the temperature increases, this dependence is lost, and a horizontal line can be scribed through all the isothermal data points. At $70{ }^{\circ} \mathrm{C}$, two anomalous data points appear, lying above the horizontal line drawn through the other data points. These straggling points correspond to the two lowest crosslink density (40 and 60\%) flexible resins. Table I indicates the dry $T_{g}$ 's of these networks are 63 and $75^{\circ} \mathrm{C}$, respectively. Water is an efficient plasticizer of epoxy, and at $70{ }^{\circ} \mathrm{C}$, both of these wet resins are in the rubbery state. As the material passes into the rubbery state, transport is significantly enhanced by the large-scale dynamics of the network. Otherwise, the isothermal kinetics of all the glassy materials appear to be similar.

Figure 4(b) reiterates the dependence of the diffusion coefficient on the nanopore size for the same rigid, semirigid, and flexible networks (glassy-state data only). However, $D$ is now plotted as a function of the average nanopore volume $\left(v_{h}\right.$, as defined in eq $2 ; \tau_{3}$ is proportional to the nanopore radius) at $5,35,50,70$, and $90^{\circ} \mathrm{C}$. Although the distinctions between the different resins and crosslink densities are dropped in this representation, the trends are consistent with Figure 4(a). At a low temperature, the diffusion coefficient is slightly dependent on the average nanopore volume, and this diminishes with temperature. Despite the significant error bars, an exponential curve fit is applied to each isotherm. At low temperatures, a mild exponential dependence appears appropriate (linear on the logarithmic scale). However, at and above $50{ }^{\circ} \mathrm{C}$, the error bars and experimental scatter suggest a horizon- 

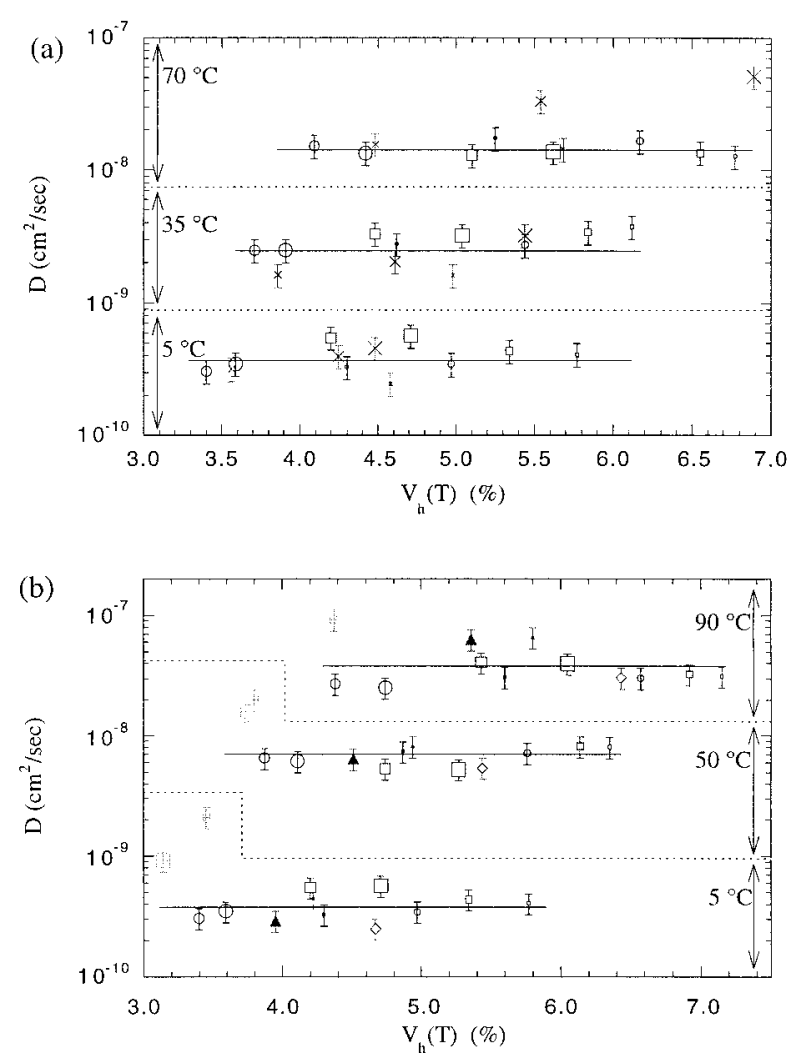

Figure 5. The diffusion coefficient is plotted as a function of the total nanopore volume fraction. (a) The same resins are included that are in Figure 4(a), with the data markers conveying the same significance. (b) The flexible resins have been omitted, and the rigidextended (triangles), extrarigid (diamonds), and nonamine (crossed squares) resins are included. These last three resin series are present only in the 100 and $60 \%$ crosslink densities, with the smallest data markers denoting the highest crosslink density.

tal line (exponent of zero) is just as appropriate. The message from these two figures is that at low temperatures, the diffusion coefficient is slightly dependent on the average nanopore volume, with this dependence diminishing with temperature.

Unlike the average nanopore size, the volume fraction of the nanopores does not correlate with the diffusion coefficient at any temperature. Figure 5(a) displays $D$ as a function of the total nanopore volume fraction, $V_{h}(T)$, for the rigid, semirigid, and flexible resins at 5,35 , and $70{ }^{\circ} \mathrm{C}$. The data markers carry the same significance as in Figure 4(a), with the circles, squares, and Xs corresponding to the rigid, semirigid, and flexible resins, respectively. As the size of the data points increases, the extent of crosslinking decreases from 100 to $40 \%$. The slight dependence of $D$ on $\tau_{3}$ at 5 and $35{ }^{\circ} \mathrm{C}$ is not mirrored with $V_{h}(T)$ in Figure 5(a). The absolute values of the diffusion coefficients do not change between Figures 4(a) and 5(a), although their ordering along the abscissa is rearranged, giving the data a randomized appearance. $D$ appears to be independent of the nanopore volume fraction at all temperatures within the glassy state. As with $\tau_{3}$, a significant increase in $D$ is observed at $70{ }^{\circ} \mathrm{C}$ for the materials above their $T_{g}$ 's. Otherwise, the diffusion coefficient appears to be dictated by the temperature of the glassy state, regardless of the volume fraction of water-molecule-sized holes.

Similar behavior is observed when the diffusion coefficients are compared to the dynamic hole volume fractions. $D$ as a function of $V_{d}(T)$ (not shown here) shows the same independence for measurements in the glassy state. Switching the comparison to the intrinsic hole volume fraction $\left(V_{0}\right.$; also not shown here) does not change the interpretation. By and large, the diffusion coefficients in the rigid, semirigid, and flexible resins are dictated by the temperature of the glassy state, regardless of the volume fraction of the nanopores.

However, to conclude that the temperature of the glassy state uniquely establishes the diffusion coefficient is premature. Thus far, the rigid-extended, extrarigid, and non-amine resins have been ignored. Figure 5(b) repeats the comparison of Figure 5(a) for the rigid (circles) and semirigid (squares) resins (the flexible resins are now omitted) with the addition of the rigid-extended (triangles), extrarigid (diamonds), and non-amine (crossed squares) resins. The last three resins are only present at 100 and $60 \%$ crosslinking, again with the larger symbols corresponding to lower crosslink densities. These isothermal measurements reiterate the independence of $D$ on $V_{h}(T)$. A horizontal line can be drawn through all of the points, with the exception of the non-amine resins. At $5{ }^{\circ} \mathrm{C}$, the diffusion coefficients of the nonamine resins are nearly one order of magnitude greater than any of the amine-containing resins. At $50^{\circ} \mathrm{C}$, the differences between the non-amine and amine resins are diminished but still significant. By $90{ }^{\circ} \mathrm{C}$, the $D$ s of the non-amine resins are within the experimental scatter of the other resins; the differences are eliminated with temperature.

The results of the absorption and desorption experiments at 35,50 , and $70{ }^{\circ} \mathrm{C}$ are presented in Table III. The desorption diffusion coefficient is significantly enhanced over the absorption value 
Table III. The Equilibrium Moisture Uptake and Diffusion Coefficients from the Absorption and Desorption Experiments and the Percentage Increase of the Desorption Diffusion Coefficient over the Absorption Value

\begin{tabular}{clccrr}
\hline Temperature & \multicolumn{1}{c}{ Resin } & $\Delta M_{\infty}(\mathrm{wt} \%)^{\mathrm{a}}$ & $D_{A}\left(\mathrm{~cm}^{2} / \mathrm{sec}\right)^{\mathrm{b}}$ & $D_{D}\left(\mathrm{~cm}^{2} / \mathrm{sec}\right)^{\mathrm{b}}$ & $\%$ Increase \\
\hline \multirow{2}{*}{$35{ }^{\circ} \mathrm{C}$} & Rigid 80\% & 2.19 & $1.70 \times 10^{-9}$ & $3.62 \times 10^{-9}$ & $113 \%$ \\
& Semirigid 40\% & 1.59 & $2.02 \times 10^{-9}$ & $3.85 \times 10^{-9}$ & $91 \%$ \\
& Flexible 60\% & 2.23 & $1.46 \times 10^{-9}$ & $3.13 \times 10^{-9}$ & $114 \%$ \\
& Non-Amine 100\% & 1.06 & $1.08 \times 10^{-8}$ & $1.72 \times 10^{-8}$ & $60 \%$ \\
$50{ }^{\circ} \mathrm{C}$ & Extrarigid 100\% & 4.18 & $1.81 \times 10^{-9}$ & $3.97 \times 10^{-9}$ & $119 \%$ \\
& Rigid 80\% & 2.50 & $2.63 \times 10^{-9}$ & $6.61 \times 10^{-9}$ & $151 \%$ \\
& Semirigid 40\% & 1.88 & $3.12 \times 10^{-9}$ & $8.14 \times 10^{-9}$ & $161 \%$ \\
& Flexible 60\% & 2.45 & $2.64 \times 10^{-9}$ & $6.49 \times 10^{-9}$ & $146 \%$ \\
$70{ }^{\circ} \mathrm{C}$ & Non-Amine 100\% & 1.22 & $1.29 \times 10^{-8}$ & $2.87 \times 10^{-8}$ & $122 \%$ \\
& Extrarigid 100\% & 4.70 & $2.70 \times 10^{-9}$ & $6.78 \times 10^{-9}$ & $151 \%$ \\
& Rigid 80\% & 2.54 & $6.85 \times 10^{-9}$ & $2.23 \times 10^{-8}$ & $225 \%$ \\
& Semirigid 40\% & 2.07 & $5.54 \times 10^{-9}$ & $1.91 \times 10^{-8}$ & $245 \%$ \\
& Flexible 60\% & 2.70 & $5.71 \times 10^{-9}$ & $2.74 \times 10^{-8}$ & $380 \%$ \\
& Non-Amine 100\% & 1.33 & $3.40 \times 10^{-8}$ & $7.34 \times 10^{-8}$ & $116 \%$ \\
& Extrarigid 100\% & 4.66 & $6.06 \times 10^{-9}$ & $1.95 \times 10^{-8}$ & $222 \%$ \\
\hline
\end{tabular}

Each coefficient is the average of three independent samples.

a Typical error $= \pm 0.07 \mathrm{wt} \%$.

b Typical error $= \pm 20 \%$.

in each of the resins. Depending on the resin and temperature, the enhancement ranges from 60 to $380 \%$. As with the absorption measurements, the desorption kinetics do not correlate with either the size or volume fraction of the nanopores. We sought potential topology-transport correlations after using the absorption diffusion coefficient $\left(D_{A}\right)$, the desorption diffusion coefficient $\left(D_{D}\right)$, the ratio of $D_{A} / D_{D}$, and the percentage increase in $D_{D}$ over $D_{A}$.

\section{DISCUSSION}

In general, very few correlations are observed between the nanopore characteristics of the epoxy and the kinetics of moisture transport. The diffusion coefficient is essentially independent of the volume fraction of the nanopores, and only at low temperatures is a slight dependence of $D$ on the average nanopore radius observed. This is somewhat unsatisfying for several reasons. First, our previous publication ${ }^{30}$ demonstrates how the nanopores are integral to transport. The equilibrium uptake increases with the intrinsic hole volume fraction, implying that water resides in the nanopores. This is further suggested by other researchers in the field who use dilatometry to monitor the moisture absorption process and report the volume of mixing to be less than ideal. ${ }^{10}$ Thus, filling in the unoccupied volume regions is anticipated.

Furthermore, free-volume theories of transport clearly predict that the diffusion coefficient should increase exponentially with the free-volume content. Although the original free-volume concept with respect to diffusion was intended to describe small-molecule diffusion in liquids, ${ }^{39}$ extensions of the model to transport in the glassy state have been proposed, as described in three comprehensive reviews. ${ }^{40-42}$ In this respect, one might anticipate a more definitive correlation between the unoccupied volume measured by the PALS technique and $D$.

However, the PALS technique is not a direct measurement of free volume, as is commonly assumed in the literature. An example of this is offered by PALS measurements on semicrystalline polyethylene terephthalate $(\mathrm{PET})^{43,44}$ that show that the PALS technique actually samples some of the unoccupied volume in the crystalline phase of PET, and thus not free for redistribution. However, a portion of the unoccupied volume detected by the PALS technique in a glassy polymer will certainly be free volume [especially with regards to the dynamic component $V_{d}(T)$ measure here], and a better correlation is, therefore, anticipated.

Other researchers used the PALS technique and claimed a correlation between the free vol- 
ume and moisture transport in epoxy. For example, Granata and coworkers ${ }^{45-47}$ reported a correlation between the free-volume fraction, as measured by PALS, and the equilibrium moisture uptake. However, in their work a series of four epoxies were used with variations in both the curing agent and the epoxy. Such a scenario also leads to possible variations in the polarity of the resin, which has a significant influence on uptake. It is not clear whether their trend of an increased uptake should be attributed to polarity or free volume.

Ito and coworkers ${ }^{48-50}$ also used PALS to study the problem of moisture absorption in epoxies and claimed the diffusion coefficient has an Arrhenius activation with the free-volume fraction. However, as with Granata and coworkers, their work is based on a series of four epoxies (a different series) in which it is unclear how the concentration of polar species varies. Furthermore, they did not measure a true diffusion coefficient. They claimed that the initial increase of weight per unit time, $\Delta M / \Delta t$, is a measure of the diffusion coefficient. However, this parameter will change with extrinsic parameters such as the sample dimensions and is not a material property like a diffusion coefficient. The experimental detail to properly convert their values to an actual diffusion coefficient is lacking in their work. Furthermore, as is demonstrated shortly, a very different interpretation can be obtained when one focuses on the initial stages of moisture uptake. In this respect, the lack of agreement between our results presented here and these preceding efforts is not great cause for concern. The study presented herein is on a larger number of resins with a better systematic control of the polarity.

As mentioned previously, it is somewhat disturbing that a better correlation between the nanopore characteristics and the kinetics of transport is not observed. Intuitively, the volume fraction of water-molecule-sized pores should influence the kinetics of transport. An explanation for this lack of dependence can be postulated by careful consideration of the few instances where a correlation between transport and topology are observed. In this work, a slight correlation between the average nanopore size and $D$ is observed, but only at low temperatures. In the previous article ${ }^{30}$ there was also a dependence of the equilibrium uptake on $V_{0}$, which, in a similar fashion, was strongest at low temperatures. The topology is always quantified in the dry state, before water is introduced into the matrix. The actual diffusion coefficient measurement can take anywhere from a few days (at $90{ }^{\circ} \mathrm{C}$ ) to several months $\left(\right.$ at $5^{\circ}$ ). In the previous publication, ${ }^{30}$ physical aging experiments clearly demonstrated the ability of water to reorganize the structure of the epoxy. In this light, one should question the relevance of the topology, or the nanopores, of the dry epoxy to transport, especially at long times. The introduction of water can modify the topology. The fact that the strongest correlations are observed at low temperatures, where water has less propensity to change the matrix, further suggests that modifications of the nanopores are an issue. This would be consistent with the strongest correlations between the equilibrium uptake and topology occurring with the $V_{0}$ component of the nanopores. In the previous publication, ${ }^{30}$ we emphasized that a large source of the $V_{0}$ unoccupied volume comes from the steric hindrances induced by the covalent crosslinks. Absorbed water cannot alter these restrictions, and $V_{0}$ may be the one portion of the nanopores that water cannot change.

\section{Initial Kinetics of Absorption}

As discussed previously, measuring the diffusion coefficient from an absorption experiment requires a knowledge of both the initial slope of the weight-gain profiles in Figure 2 and the equilibrium uptake, a process that takes a long time to complete. Obviously, this calculation is made under the assumption that $D$ does not change during the absorption process. Given the notion that water may be able to alter the nanopores, it is desirable to have an estimation of the transport kinetics in the initial stages of uptake when water may not have had the time to alter the topology and the dry nanopore structure may be of more relevance.

The initial slope of an $M_{t}$ versus $t^{1 / 2} / h$ plot (the same plot used to determine the diffusion coefficient) is used to determine the initial absorption rate. The units of this slope are $\mathrm{mg} \mathrm{H}_{2} \mathrm{O} \cdot \mathrm{cm} /$ $\min ^{1 / 2}$. However, if the sample thickness is doubled, this slope is doubled, which does not imply the initial kinetics is twice as fast. For this reason, the slope must be normalized by the sample thickness. By the same token, a sample with a surface area of $1 \mathrm{~cm}^{2}$ will pick up less moisture than a $2-\mathrm{cm}^{2}$ sample. The aforementioned slope should be further normalized by the diffusion area. Dividing the initial slope by both the sample thickness and diffusion area yields the initial 

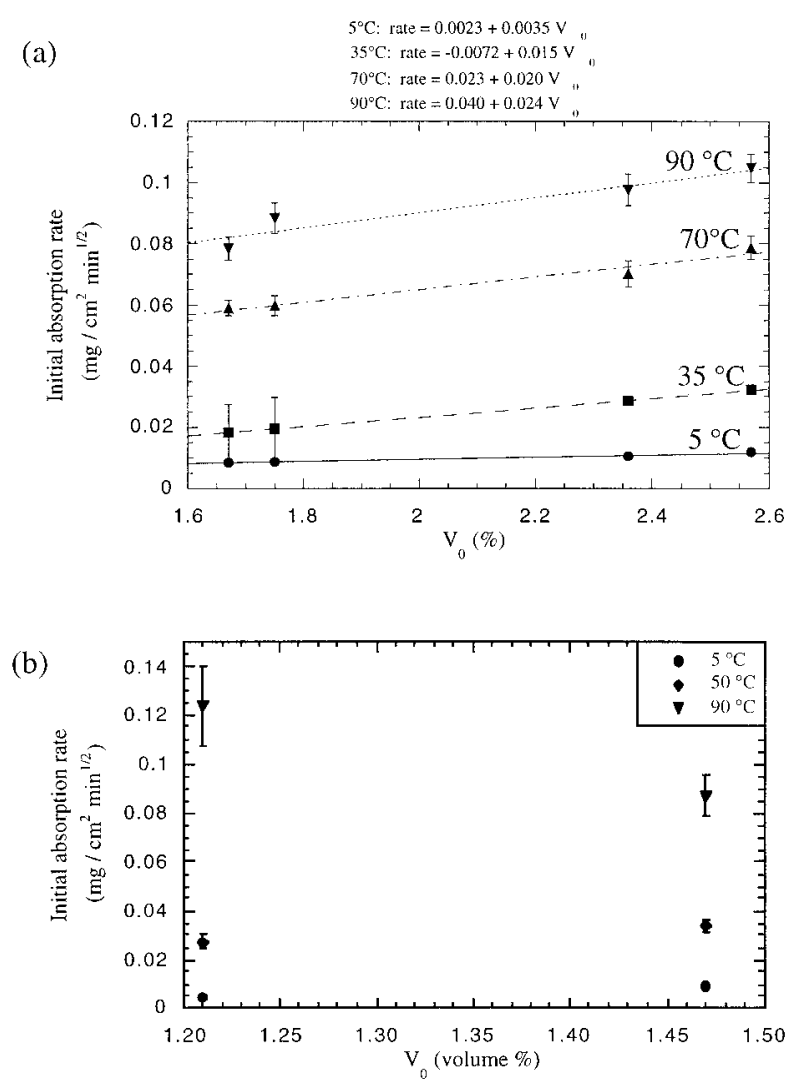

Figure 6. The initial absorption rate as a function of the intrinsic hole volume fraction for various temperatures ( $V_{0}$ increases when the crosslink density increases). (a) The results for the rigid resins are presented where all the resins remain in the glassy state, and a clear correlation can be observed. (b) The results for the non-amine resins are presented, showing a similar dependence of the initial absorption rate on $V_{0}$, except at $90^{\circ} \mathrm{C}$. At this temperature, the lowest crosslink density sample enters the rubbery state, and the correlation is lost.

sorption rate, the units of which are $\mathrm{mg} \mathrm{H}_{2} 0 / \mathrm{cm}^{2}$ $\min ^{1 / 2}$. This initial sorption rate is analogous to a flux, the units of which are $\mathrm{mg} \mathrm{H}_{2} \mathrm{O} / \mathrm{cm}^{2} \mathrm{~min}$. Both measure the number of solvent molecules passing through an area per unit of time.

As with the diffusion coefficient data, the initial absorption rate data is analyzed in terms of the nanopore volume fractions. Just as with $D$, a correlation is not observed between the initial absorption rate and either the total or dynamic hole volume fractions; the initial absorption rate appears independent of both $V_{h}(T)$ and $V_{d}(T)$. However, a clear dependence is observed between the initial absorption rate and $V_{0}$, as demonstrated in Figure 6 [this suggests $V_{d}(T)$ dominates
$V_{h}(T)$ ] as $\left.V_{h}(T)=V_{0}+V_{d}(T)\right)$. Figure 6(a) plots the initial absorption rate as a function of $V_{0}$ for the rigid resin series at several temperatures. The initial absorption rate increases with $V_{0}$, and the magnitude of this dependence increases with temperature. Although they are not shown here, similar behavior is observed with the other resins, as long as the wet material remains in the glassy state. Figure 6(b) shows a similar plot for the non-amine resin, where this effect of the glass transition is visible. The two data points at each isotherm correspond to the 60 and $100 \%$ crosslinked samples with the higher crosslink density possessing the larger $V_{0}$ and anhydrous $T_{\text {o }}$ 's of 70 and $140{ }^{\circ} \mathrm{C}$, respectively. At 5 and $50^{\circ} \mathrm{C}$, all of the samples are in the glassy state, and the initial absorption rate appears to increases with $V_{0}$ (albeit this statement is based on just two data points). However, at $90^{\circ} \mathrm{C}$, the low crosslink density sample enters the rubbery state, and the correlation is lost.

Excluding the measurements from the rubbery state, there appears to be a correlation between the initial absorption rate and the intrinsic hole volume fraction. This is reassuring as intuition suggests that the water-molecule-sized holes should influence the kinetics of transport. However, the correlation must be made before the water has a chance to alter the topology. Conditions favoring such a correlation might include the initial stages of uptake and highly rigid resins where the nanopores are not easily reconstructed by the water. Although it was not examined here, it is surmised that a low moisture activity (low relative humidity) might produce a similar dependence of the kinetics on topology.

\section{Polarity and the Kinetics of Transport}

Thus far, the lack of a stronger correlation between the equilibrium kinetics and the topology has been rationalized in terms of the changes in the topology that can occur when water enters the epoxy. Although it is true that a better correlation is observed when the comparisons are restricted to the initial stages of absorption, one must also consider the influence of polarity on the equilibrium kinetics. After all, the previous article ${ }^{30}$ on the equilibrium uptake describes how the nanopores open the matrix and facilitate access of the water molecules to the polar sites. In other words, the polarity and topology must be considered in tandem. 
In Figure 5(b), the role of polarity is emphasized. The majority of the resins in this figure are cured with amine-based curing agents and, therefore, contain the polar hydroxyls and amines, with the exception of the non-amine resins, which are cured with an anhydride-based curing agent. These anhydride-cured resins contain less polar ether and ester linkages that do not have as strong an affinity for water as the amine-cured resins. Correspondingly, the diffusion coefficients at low temperatures are nearly one order of magnitude greater in the non-amine resins. This is because the polar sites in the amine-cured resin provide trapping sites that cause the water to stop and interact, thus hindering diffusion. If the trapping sites are removed, diffusion is enhanced as seen with the non-amine resins. Another way to overcome the trapping sites is to increase the kinetic energy of the water molecules. As the temperature is raised, thermal energy $(\mathrm{kT})$ increases, and the more energetic water molecules are less likely to reside in a potential energy well or trapping site provided by the polar groups; correspondingly, the difference in $D$ between the amine-based and non-amine resins is diminished.

The diffusion process is known to be influenced by many factors (polarity, topology, molecular motions, etc.). Generally speaking, one factor has the dominant or rate-limiting influence. We must consider the possibility that the lack of a correlation between the nanopore content and the transport kinetics is due to the polar trapping sites being the rate-limiting factor. Perhaps if a large series of nonpolar epoxies are studied, a better correlation between the transport kinetics and topology will be observed. It is also possible that the transport of a nonpolar penetrant molecule of similar dimensions to water, such as methane or diatomic hydrogen, would exhibit a stronger dependence on topology. Such experiments would provide additional insight into the mechanisms of moisture transport in epoxy.

It is interesting to compare the magnitudes of the initial absorption rate between the aminecontaining resin in Figure 6(a) and the non-amine resins in Figure 6(b). These two values are quite comparable, whereas the diffusion coefficients of the non-amine resin were nearly one order of magnitude greater at low temperatures [see Fig. 5(b)]. This emphasizes that the increase in the initial absorption rate with $V_{0}$ is truly a volumic effect; specific water-epoxy interactions have very little significance in establishing the initial absorption rate. The initial flux of water into the epoxy depends on how open the matrix is, which makes intuitive sense. A more porous structure should provide more locations for water to enter.

\section{Absorption and Desorption Behavior}

The intent of the absorption and desorption experiments was to further disclose the role of the polar groups in establishing the kinetics of transport. The hydroxyls and amines provide water trapping sites, thus influencing transport. Hayward et al. ${ }^{51}$ monitored the absorption process in situ using dielectric spectroscopy and reported that the initial water molecules are bound to the hydroxyls. By bound, they meant that the relaxation frequency of absorbed water is hindered, as dictated by the hydroxyl-water interactions. Only in the final stages of absorption are free or more mobile water molecules observed. This has implications for the kinetics of sorption because in the initial stages of absorption, the kinetics are retarded as the polar sites become saturated. In the later stages of sorption, free water molecules are present, and the steady-state transport is enhanced. When measuring the diffusion coefficient on absorption, the initial slope of a $\Delta M_{t}$ versus $t^{1 / 2} / h$ curve emphasizes the kinetics during the polar-site saturation stage. However, by measuring the diffusion coefficient on desorption, the initial slope emphasizes the equilibrium state where the steady-state transport is dominated by free water.

Table III demonstrates the difference between kinetics during the saturation (on absorption: $D_{A}$ ) and steady-state (on desorption: $D_{D}$ ) stages. The diffusion coefficient is significantly enhanced on desorption. Although it is tempting to interpret these results solely in terms of the free and bound water, other factors must be considered. Throughout this and the previous article, the ability of water to reshape the topology is underscored. In comparing the initial and steady-state diffusion coefficients, one must consider this reorganization. Figure 7 shows the percentage increase of the diffusion coefficient on desorption (over absorption) as a function of temperature. A discussion of this figure is useful for isolating the effects mentioned previously.

To begin this discussion, focus on the low-temperature portion of Figure 7 . At $35{ }^{\circ} \mathrm{C}$, the percentage increase values mirror the resin polarity. The smallest increase is observed in the nonamine resin, which has the lowest polarity, whereas the greatest increase occurs in the ex- 


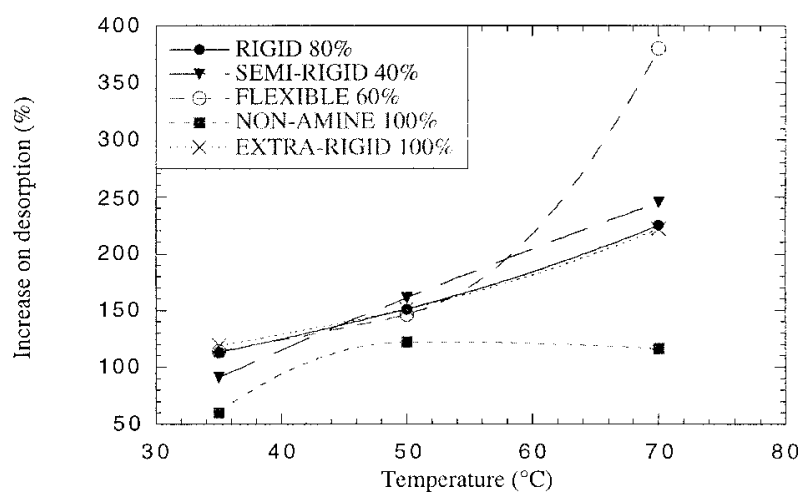

Figure 7. The percentage increase in the moisture diffusion coefficient as a function of temperature when the measurements are made on desorption as opposed to absorption.

trarigid resin, the resin with the highest polarity. This is consistent with the previous discussion on the bound and free water. In the non-amine resin, the mildly polar ether and esters do not provide strong trapping sites. The first water molecules to be absorbed are much closer to being free, so the increase in mobility in the later stages of absorption is not as significant. However, in the initial uptake of the extrarigid resin, the molecules are tightly bound to the polar hydroxyls, leading to large differences in the desorption kinetics once the polar sites are saturated.

The effectiveness of the trapping sites depends on the kinetic energy of the water molecule. If the kinetic energy increases, the water will spend less time in each potential energy well and more time in a nearly free state. This kinetic energy $(\mathrm{kT})$ increases linearly with temperature. As long as the shape of the potential well does not change significantly with temperature, the escape tendency will also increase linearly with temperature. In Figure 7, the percentage increase on desorption mimics this linear increase with temperature in the extrarigid, rigid, and semirigid resins. Such behavior suggests the fraction of bound water at equilibrium uptake decreases linearly with temperature as evidenced by the enhanced desorption coefficient (the similar isothermal absorption diffusion coefficients presented in Table II imply the changes are primarily in the desorption values). However, solid-state NMR, dielectric spectroscopy, or inelastic neutron scattering measurements should be performed to confirm this notion.

These arguments are contingent on the resin remaining in the glassy state. For the flexible resin (60\% crosslinked: a dry $T_{g}$ of $75{ }^{\circ} \mathrm{C}$ ), the 35 and $50{ }^{\circ} \mathrm{C}$ measurements are in the glassy state, and in Figure 7, the increase is similar to the other amine-containing resins. However, at $70^{\circ} \mathrm{C}$, the wet flexible resin enters the rubbery state, and a massive increase in the desorption coefficient is observed. This increase is misleading because the initial slope of the absorption curve comes from the glassy state. It would be interesting to extend this comparison to $90{ }^{\circ} \mathrm{C}$ to observe how much the desorption coefficient increases when both the absorption and desorption measurements are performed in the rubbery state. One might anticipate a less significant increase for comparisons in the rubbery state.

The negative deviation from linearity at high temperatures in the non-amine resin in Figure 7 has yet to be explained. The phenomenon of clustering ${ }^{41,52-54}$ appears to capture this negative deviation. Water is a highly polar molecule, and clustering can reduce energy significantly. In highly polar epoxies, these interactions are afforded by the matrix. In the mildly polar nonamine resin, it is plausible that the water-water interactions are more attractive than epoxy-water, inducing water clusters at the higher uptake levels. This notion is supported by the reports that clustering is favored in less polar epoxies. ${ }^{55}$ On clustering, the effective diameter of the water molecule increases, and the diffusion coefficient decreases. It is more difficult for a cluster of several molecules to diffuse through the nanopores than for a lone, free water molecule. This is consistent with the negative deviation from linearity at high temperatures for the non-amine resins in Figure 7. This might suggest that on absorption, the water is initially absorbed as lone molecules. However, on desorption, they tend to move as clusters and, thus, at a somewhat reduced rate. However, this description is purely based on phenomenology and remains to be verified by an experimental technique, such as inelastic neutron scattering, that probes the local diffusive motions of water. These measurements are currently in progress.

\section{CONCLUSIONS}

By creating a series of epoxies in which the molecular topology is systematically altered without introducing significant changes in the overall resin polarity, we have been able to evaluate the role of topology in determining the kinetics of 
moisture transport. The topology of the dry epoxy is quantified in terms of both the size and volume fraction of nanopores $5-6 \AA$ in diameter, as evidenced by the PALS technique. As these nanopores are commensurate with the 3-Å kinetic diameter of a water molecule, one would anticipate their presence to have a strong influence on the kinetics of transport. However, contrary behavior is observed. Isothermally, the diffusion coefficient appears independent of the volume fraction of the nanopores. There is a slight exponential dependence of the diffusion coefficient on the average nanopore size, but this persists only for temperatures below $50{ }^{\circ} \mathrm{C}$. As the nanopores are measured in the dry epoxy resins, it is surmised that part of the reason for a lack of correlation between the kinetics of transport and the nanopore content is the result of moisture absorption altering the nanopores, rendering the dry nanopore characteristics irrelevant to transport. This is consistent with previous physical aging experiments that suggest water can alter the epoxy structure sufficiently to erase physical aging. To further support this notion, a better correlation is observed between the initial absorption rate (analogous to initial flux) and the intrinsic, or absolute zero, hole volume fraction. In the initial stages of absorption, moisture does not have the time to alter the topology, and the dry nanopore characteristics are more germane to transport. This is also consistent with the weak exponential dependence of $D$ on the average nanopore size only at low temperatures; low temperatures also make it more difficult to reorganize the nanopore networks. Although it is tempting to accept this explanation based on the ability of water to reorganize the epoxy topology, one must also be aware of the influence of specific polar interactions between the water and the epoxy. It has been demonstrated that the nanopores are most likely coincident with the polar groups and that these polar groups provide trapping sites for diffusing water molecules. The possibility that these trapping sites are the rate-limiting factor in the diffusion process cannot be ignored. This could also describe why the diffusion coefficient is more or less independent of the nanopore content.

The authors would like to thank the Air Force Office of Scientific Research for funding this research under Grant F-49620-95-1-0037. Furthermore, we appreciate the constructive criticism provided by Professors Richard Robertson and David Srolovitz of the University of Michigan, Professor Andre Lee of Michigan State Uni- versity, Professor Annelise Faivre of the Université Montpellier II, Dr. Brett Bolan, and Dr. Hristo Hristov.

\section{REFERENCES AND NOTES}

1. Browning, C. E. Polym Eng Sci 1978, 18, 16.

2. Mostovoy, S.; Ripling, E. J. J Appl Polym Sci 1971, $15,641$.

3. Diggwa, A. D. S. Polymer 1974, 15, 101.

4. Pritchard, G.; Rose, R. G.; Taneja, N. J Mater Sci 1976, 11, 718.

5. Young, R. J.; Beaumont, P. W. R. J Mater Sci 1976, 11, 776.

6. Young, R. J.; Shortall, J. B. J Mater Sci 1976, 11, 1113.

7. Yamai, S.; Young, R. J. Polymer 1975, 18, 1075.

8. Morgan, R. J.; O’Neal, J. E. Polym Plast Technol Eng 1978, 10, 49.

9. Morgan, R. J.; O’Neal, J. E.; Fanter, D. L. J Mater Sci 1980, 15, 751.

10. McKague, E. L.; Reynolds, J.; Halkias, J. E. J Appl Polym Sci 1978, 22, 1643.

11. Adamson, M. J. J Mater Sci 1980, 15, 1736.

12. Diamant, Y.; Marom, G.; Broutman, L. J. J Appl Polym Sci 1981, 26, 3105.

13. Dewimille, D.; Bunsell, A. R. J Phys D: Appl Phys 1982, 15, 2079.

14. Henson, M. C.; Weitsman, Y. In Composites '86, Recent Advances in Japan and the United States; Kawata, K.; Unekawa, S.; Kobayahsi, A., Eds.; Japan Society for Composite Materials, Tokyo, 1986; p 775.

15. Lee, M. C.; Peppas, N. A. J Compos Mater 1993, 27, 1146.

16. Lee, M. C.; Peppas, N. A. J Appl Polym Sci 1993, 47, 1349.

17. Amer, M. S.; Koczak, M. J.; Galiotis, C.; Schadler, L. S. Adv Com Lett 1994, 3, 17.

18. Zhou, J.; Lucas, J. P. Compos Sci Technol 1995, 53, 57.

19. Apicella, A.; Nicolais, L.; Astarita, G.; Drioli, E. Polymer 1979, 20, 9.

20. Apicella, A.; Nicolais, L.; Astarita, G.; Drioli, E. Polymer 1981, 22, 1064.

21. Apicella, A.; Nicolais, L. Ind Eng Chem Prod Res Dev 1981, 20, 138.

22. Morgan, R. J.; O’Neal, J. E.; Fanter, D. L. J Mater Sci 1980, 15, 751.

23. DéNève, B.; Shanahan, M. E. R. Polymer 1995, 34, 5099.

24. Xiao, G. Z.; Shanahan, M. E. R. J Polym Sci Part B: Polym Phys 1997, 35, 2659.

25. Morel, E.; Bellenger, V.; Verdu, J. Polymer 1985, 26, 1719

26. Burton, B. L. Proc. 18th International SAMPE Technical Conference, Oct. 7-9, 1986; Society for 
the Advancement of Materials Process Engineering; Covina, California; v 18, pp 124-134.

27. Van Krevelen, D. W. In Properties of Polymers; Elsevier: Amsterdam, 1976; p 420.

28. Goldsmith, J. R. J Geol 1950, 58, 518.

29. Davis, M. E.; Montes, C.; Hathaway, P. E.; Arhancet, J. P.; Hasha, D. L.; Garces, J. M. J Am Chem Soc 1989, 111, 3919.

30. Soles, C. L.; Chang, F. T.; Bolan, B. A.; Hristov, H. A.; Gidley, D. W.; Yee, A. F. J Polym Sci Part B: Polym Phys 1998, 36, 3035.

31. Hamielec, A. E.; Eldrup, M.; Mogensen, O.; Jansen, P. J Macromol Sci Rev Macromol Chem 1973, C9, 305.

32. Nakanishi, H.; Jean, Y. C. In Positron and Positronium Chemistry; Schrader, D. M.; Jean, Y. C., Eds.; Elsevier Science: Amsterdam, 1988; Chapter 5.

33. Pethrick, R. A. Prog Polym Sci 1997, 22, 1.

34. Tao, S. J. J Chem Phys 1972, 56, 5499.

35. Eldrup, M.; Lightbody, D.; Sherwood, J. N. Chem Phys 1981, 63, 51.

36. Crank, J.; Park, G. S. In Diffusion in Polymers; Crank, J.; Park, G. S., Eds.; Academic: London, 1968; Chapter 1.

37. Shen, C. H.; Springer, G. S. J Compos Mater 1976, 10, 2.

38. Merritt, M. E.; Heux, L.; Halary, J. L.; Schaefer, J. Macromolecules 1997, 30, 6760.

39. Cohen, M. H.; Turnbull, D. J Chem Phys 1959, 31, 1164.

40. Park, G. S. In Diffusion in Polymers; Crank, J.; Park, G. S., Eds.; Academic: London, 1968; Chapter 5.

41. Vieth, W. R. Diffusion In and Through Polymers; Hanser: New York, 1991; pp 35-42.
42. Duda, J. L.; Zielinski, J. M. In Diffusion in Polymers; Neogi, P., Ed.; Marcel Dekker: New York, 1996; Chapter 3.

43. Xie, L.; Gidley, D. W.; Hristov, H. A.; Yee, A. F. Polymer 1994, 35, 14.

44. Hristov, H. A.; Soles, C. L.; Bolan, B. A.; Gidley, D. W.; Yee, A. F. Polym Mater Sci Eng 1997, 76, 431.

45. MacQueen, R. C.; Grananta, R. D. J Polym Sci Part B: Polym Phys 1993, 31, 971.

46. MacQueen, R. C.; Grananta, R. D. Prog Org Coat 1996, 28, 97.

47. Madani, M. M.; Miron, R. R.; Granata, R. D. J Coat Technol 1997, 69, 872.

48. Suzuki, T.; Oki, Y.; Numajira, M.; Miura, T.; Kondo, K.; Shiomi, Y.; Ito, Y. J Appl Polym Sci 1993, 49, 1921.

49. Suzuki, T.; Oki, Y.; Numajira, M.; Miura, T.; Kondo, K.; Shiomi, Y.; Ito, Y. Polymer 1996, 37, 3025.

50. Miura, T.; Suzuki, T.; Oki, Y.; Numajira, M.; Kondo, K.; Shiomi, Y.; Ito, Y. J Phys IV 1993, 3, 249.

51. Hayward, D.; Hollins, E.; Johncock, P.; McEwans, I.; Pethrick, R. A.; Pollock, E. Polymer 1997, 38, 1151.

52. Zimm, B. H.; Lundberg, J. L. J Phys Chem 1956, 60,425 .

53. Lundberg, J. L. J Macromol Sci Phys 1969, B3, 693.

54. Starkweather, H. W. J Polym Sci 1963, B1, 133.

55. Aronhime, M. T.; Peng, X.; Gillham, J. K.; Small, R. D. J Appl Polym Sci 1986, 32, 3589. 